Jurnal Agribis

Vol. 7, No.2,Oktober Tahun 2021

\title{
RESPON KELOMPOK TANI TERHADAP PERAN PPL / PENYULUH PERTANIAN LAPANGAN DI KECAMATAN KALIDAWIR, KABUPATEN TULUNGAGUNG
} Abdul Rochman

\author{
Program Studi Agribisnis, Fakultas Pertanian, Universitas Tulungagung \\ Email: abdulrochman2024@gmail.com
}

\begin{abstract}
ABSTRAKSI
Perkembangan dibidang teknologi pertanian pada saat ini telah memberikan banyak kontribusi dibidang pertanian. Namun ternyata belum banyak dinikmati oleh para petani. Ini karena ada beberapa kendala diantarnya rendahnya pengetahuan para petani dan keterbatasan dibidang sumber daya seperti modal, tanah dan lainlain. Respon kelompok tani terhadap peran PPL tentu mampu menciptakan terjadinya hubungan yang serasi yang bersifat interpersonal antara kelompok tani dan PPL. Ada faktor-faktor intern dan ekstern yang berpengaruh pada respon kelompok tani terhadap PPL. Faktor intern meliputi sifat stereotip, kearifan terkait menyunting stimulus, konsep tentang diri, kebutuhan dan harapan, emosi tentang diri dan pengalaman di masa lalu. Faktor ekstern antara lain : intensitas kunjungan, frekuensi kunjungan dan ukuran maupun pengulangan kunjungan. Dari hasil penelitian dapat dilihat bahwa faktor intern ataupun faktor ekstern tidak mempunyai hubungan dengan respon petani, namun hubungannya sangat kuat dengan peran PPL dan hasil analisa terdapat hubungan respon para petani terhadap peran PPL. Hasil penelitian menunjukkan bahwa PPL sebagai pembimbing mempunyai kategori tinggi dengan skor $71,3 \%$, PPL sebagai organisator mempunyai kategori sedang dengan skor $60,7 \%$, PPL sebagai dinamisator mempunyai kategori tinggi dengan skor $81,3 \%$ dan PPL sebagai teknisi mempunyai kategori sedang dengan sekor $62,3 \%$. Adapun saran dari penelitian ini meliputi : perlunya suasana yang kondusif antara para kelompok petani dengan PPL.
\end{abstract}

Kata kunci : Peran PPL, respon petani, faktor intern dan ekstern petani

\begin{abstract}
Developments in the field of agricultural technology at this time have contributed a lot in the field of agriculture. However, it has not been widely enjoyed by farmers. This is because there are several obstacles including the low knowledge of farmers and limitations in the field of resources such as capital, land and others. The response of farmergroups to the role of PPL is certainly able to create a harmonious interpersonal relationship between farmer groups and PPL. There are internal and external factors that influence the response of farmer groups to PPL. Internal factors include the nature of stereotypes, wisdom related to editing the stimulus, self-concept, needs and expectations, emotions about oneself and past experiences. External factors include: intensity of visits, frequency of visits and the size and repetition of visits. From the results of the study, it can be seen that internal factors or external factors do not have a relationship with the response of farmers, but the relationship is very strong with the role of PPL and the results of the analysis show that there is a relationship between the responses of farmers to the role of PPL. The results showed that PPL as a supervisor had a high category with a score of $71.3 \%, P P L$ as an organizer had a
\end{abstract}


medium category with a score of $60.7 \%, P P L$ as a dynamist had a high category with a score of $81.3 \%$ and PPL as a technician had a medium category with score $62.3 \%$. The suggestions from this research include: the need for a conducive atmosphere between farmer groups and PPL.

Keywords: PPL role, farmer response, internal and external factors of farmers

\section{PENDAHULUAN}

Perkembangan ekonomi di Indonesia dalam sejarahnya, baik dalam perspektif lapangan kerja, sumber pendapatan dan devisa negara maupun sebagai sumber pertumbuhan ekonomi, maka sektor pertanian memegang peran yang strategis. Ada tiga elemen dasar yaitu petani, pertumbuhan produksi pertanian dan lahan yang dimiliki merupakan unsur fundamental pertanian. Namun demikian kenyataan menunjukkan bahwa posisi petani ternyata masih tertinggal bila dibandingkan dengan sektor di luar pertanian dan ini merupakan sebuah gambaran pembangunan pertanian di Indonesia saat ini.

Untuk memberikan kemakmuran masyarakat, maka tidak akan tercapai bila sektor pertanian masih konvesional dari sinilah pertanian menjadi titik sentral dalam pembangunan di daerah pedesaan. Dengan kata lain prinsip-prinsip yang digunakan pertanian modern belum digunakan, karena terbatasnya pengetahuan petani. Itulah sebabnya perlu adanya peningkatan kemampuan petani melalui berbagai upaya antara lain pendidikan, latihan dan penyuluhan dengan maksud agar petani menjadi berubah sikap menjadi mampu dan mau dalam menjalankan usahataninya serta merubah cara pertanian subsisten atau tradisional berubah menjadi lebih modern.

Sumbangan teknologi terutama dibidang pertanian ternyata memberikan kontribusi yang besar dalam bidang pertanian. Permasalahannya adalah peningkatan teknologi belum banyak diterima oleh para petani secara keseluruhan. Ada beberapa kendala diantaranya adalah tingkat pengetahuan petani masih rendah, kemudian sumber daya antara lain modal dan tanah masih juga rendah, sehingga terdapat kesenjangan informasi dan teknologi antara lain misalnya dari institusi bidang penelitian dengan sasaran teknologi oleh petani. Upaya untuk menanggulangi ketimpangan informasi, maka dibutuhkan tranfer teknologi yang berjalan secara lancar dengan misalnya melalui peran PPL (Penyuluh Pertanian Lapangan).

Pembangunan pertanian menjadi ujung tombak bagi proses pembangunan di 
Indonesia dengan hadirnya Penyuluh Pertanian Lapangan. Namun dengan adanya otonomi daerah maka tugas dan fungsi Penyuluh Pertanian Lapangan menjadi kabur karena tugas dan fungsi maupun peran dan peran Penyuluh Pertanian Lapangan kurang jelas. Dalam hal ini peran kelompok tani sebagai dalam kedudukannya sebagai kelompok informal dalam masyarakat sesungguhnya merupakan kumpulan petani yang melaksanakan interaksi dengan harapan dapat meningkatkan kemajuan dan peningkatan kepemimpinan kelompok tersebut. Kelompok tani ternyata juga mampu memberi arahan pada upaya peningkatan etos kerja sama diantara petani sehingga harapannya ada peningkatan proses difusi, inovasi, terhadap teknologi baru yang semakin cepat. Faktor intern ini secara keseluruhan mampu mempengaruhi perilaku kelompok tersebut dan punya peran penting dalam proses pengambilan keputusan diantara mereka. Disisi lain ada faktor-faktor ekstern diluar kelompok tani yang mampu memberikan keterkaitan dengan karakteristik yang timbul dari stimulus. Disini yang dimaksud stimulus merupakan peran PPL dalam mendampingi kelompok tani.

\subsection{Permasalahan}

Rumusan masalah meliputi :

1. Bagaimana korelasi faktor-faktor intern dan ekstern pada respon petani?

2. Bagaimana respon petani kepada peran Penyuluh Pertanian Lapangan (PPL) ?

\subsection{Kegunaan dan Tujuan}

\subsubsection{Tujuan meliputi :}

1. Menganalisa hubungan yang terjadi antara faktor intern maupun ekstern terkait respon petani.

2. Menganalisa respon para petani kepada peran Penyuluh Pertanian Lapangan.

\subsubsection{Kegunaan penelitian ini meliputi :}

1. Menjadi referensi maupun literatur yang mampu memberikan informasi terkait respon para petani terhadap peran PPL.

2. Bahan kajian untuk PPL agar lebih kondusif dalam menyikapi maupun dalam 
menyelesaikan permasalahan yang terjadi di masyarakat petani.

3. Memberikan kontribusi bagi pemangku kepentingan dalam upaya pengambilan kebijakan di bidang pertanian, khususnya terkait program penyuluhan pertanian.

\subsection{Kerangka Pemikiran}

Tugas sebagai seorang penyuluh pertanian maka mempunyai berbagai peran diantaranya :

1. Penyuluh berperan dalam membimbing usaha tani.

2. Berperan sebagai dinamisator maupun organisator.

3. Berperan terkait teknisi

4. Mempunyai peran menjadi penghubung ( Suhardiono, 1990 )

Faktor-faktor intern yang mampu memberikan pengaruh respon kelompok tani kepada PPL diantaranya :

1. Sifat stereotip merupakan sebuah keyakinan terhadap sifat karakteristik orang atau kelompok masyarakat yang senantiasa menyamaratakan kepada seluruh anggota masyarakat tersebut. Ini terjadi terkait dengan berbagai tanggapan para petani terhadap peran PPL dalam kapasitasnya sebagai pendamping kelompok tani tersebut.

2. Kearifan stimulus

Sebuah keputusan untuk menerima sebuah inovasi atau adopsi pada umumnya dilaksanakan musyawarah yang dilaksanakan PPL, ketua kelompok tani maupun para anggota. Terkadang PPL sama sekali tidak ikut menentukan musyawarah dan tidak berpartisipasi. Dalam hal ini ketua kelompok tani mempunyai peran yang cukup penting dan dominan dalam sebuah keputusan.

3. Konsep tentang diri.

Di lapang banyak dijumpai kelompok tani kelas atas mempunyai konsep diri yang cenderung positif dibandingkan dengan kelompok lain yang ada dibawahnya.

4. Harapan dan kebutuhan

Materi yang disosialisasikan oleh PPL berhubungan dengan permasalahan budidaya dan teknis. Menentukan komoditas pertanian disesuaikan dengan kondisi yang ada di lapangan, saprodi yang disesuaikan dengan prinsip PHT 
(Pengendalian Hama Terpadu). Untuk permasalahan pasca panen maupun pemasarannya ternyata belum mendapatkan perhatian yang semestinya.

5. Terkait emosi diri.

Dalam penyuluhan yang dilaksanakan bila tidak sesuai dengan harapan petani maka akan menimbulkan perasaan yang kurang senang maupun kurang kondusif bagi para petani. Ini terkait bila PPL lebih sering menggali informasi daripada memberikan penyuluhan, ini ternyata berpengaruh terhadap emosi diri yang terbentuk pada diri petani.

6. Pengalaman masa lalu.

Pengalaman dimasa lampau dalam upaya penyuluhan pertanian pada umumnya dilaksanakan secara prinsip top down cenderung merupakan upaya pemerintah untuk mensukseskan program pemerintajh antara lain : Proyek Bimas, Insus dan lain-lain.

Faktor ekstern antara lain meliputi karakteristik stimulus diantaranya : frekuensi, intensitas, ukuran (size) dan pengulangan (repetion).

1. Frekuensi kunjungan

Frekuensi kunjungan merupakan jumlah kunjungan atau kegiatan yang dilaksanakan PPL.

2. Intensitas kunjungan

Intensitas merupakan sebuah empati atau wujud sebuah perhatian para PPL kepada kelompok binaannya.

3. Ukuran (size)

Ukuran (size) yang dilakukan PPL adalah menurut sesuai cara pandang maupun ukuran dimata para tani. Sebagai contoh ada berbagai inovasi yang disampaikan PPL kepada petani ternyata menurut petani adalah sebuah inovasi yang relatif baru, sebagai contoh PHT merupakan cara pengendalian hama terpadu yang mendasarkan pada pemakaian musuh alami untuk menanggulangi atau meminimalisasikan penggunaan pestisida kimia untuk lebih membudayakan pemakaian obat-obatan pestisida yang bersifat organik.

4. Pengulangan (Repetion)

Pengulangan adalah jumlah banyaknya upaya penyuluhan atau sosialisasi yang 
dilaksanakan oleh PPL.

\subsection{Hipotesa}

Hipotesa yang disampaikan pada pada penelitian ini meliputi :

1. Diduga ada korelasi antara faktor-faktor intern dengan faktor ekstern dengan respon petani terhadap PPL.

2. Diduga ada korelasi antara respon petani dengan peran PPL.

\section{METODE PENELITIAN}

Penelitian ini diselenggarakan di Kalidawir, Tulungagung, adapun Kecamatan Kalidawir mempunyai 17 desa, berada pada $43^{\circ}$ bujur timur, $18-51^{\circ}$ lintang selatan dengan luas $97,66 \mathrm{~km}^{2}$ dengan batas-batas sebelah :

- Utara : Sumbergempol dan Ngunut

- Timur : Pucanglaban dan Ngunut

- Selatan : Samudera Indonesia

- Barat : Boyolangu, Campurdarat, dan Tanggunggunung

Pemilihan daerah penelitian dilaksanakan secara purposive antara lain:

1. Lokasi Kalidawir cukup strategis sehingga PPL mempunyai arti penting dalam upaya pembangunan di sektor pertanian.

2. Adanya kelompok tani yang mempunyai keragaman dalam pembinaan oleh PPL.

\subsection{Waktu Penelitian}

Waktu pelaksanaan penelitian diselenggarakan mulai tanggal 10 Juni 2019 sampai dengan 20 Agustus 2010

\subsection{Penentuan Responden}

Penelitian ini menggunakan responden meliputi : PPL, kelompok tani dan seluruh petani yang ada di Kalidawir, Tulungagung. Pengambilan contoh PPL dilaksanakan dengan cara purposive dari semua PPL di wilayah di Kalidawir sebanyak 15 orang, karena peneliti mendapatkan banyak informasi. Seluruh kelompok tani di Kalidawir berjumlah 60 kelompok yang dijadikan responden. 
Metodologi Stratified Random Sampling dipakai sebagai sebuauh penentuan responden yang berarti dengan cara di strata lebih dulu berdasar kelas kelompok tani (pemula, lanjut, madya).

Penentuan jumlah responden berdasarkan rumus sebagai berikut :

$$
\mathrm{n} \text { Petani }=\frac{\mathrm{n}_{\mathrm{i}}}{\sum \mathrm{n}} \times \sum \mathrm{n} \text { Petani }
$$

n Petani : jumlah petani tiap-tiap kelas kelompok

$\mathrm{n}_{\mathrm{i}} \quad$ : jumlah kelas kelompok

$\sum \mathrm{n} \quad$ : total jumlah kelompok tani

Sn Petani : total jumlah petani

Tabel 1. Jumlah Responden.

\begin{tabular}{|c|c|c|c|}
\hline No & $\begin{array}{c}\text { Kelas Kelompok } \\
\text { Tani }\end{array}$ & $\begin{array}{c}\text { Jumlah Populasi } \\
\text { Kelompok Tani }\end{array}$ & Jumlah Responden \\
\hline \hline 1 & Pemula & 20 & 17 \\
\hline 2 & Lanjut & 30 & 18 \\
\hline 3 & Madya & 10 & 7 \\
\hline \hline \multicolumn{2}{|c|}{ Jumlah } & $\mathbf{6 0}$ & $\mathbf{4 2}$ \\
\hline
\end{tabular}

Sumber : BPP Kalidawir, 2019

\subsection{Pengumpulan Data}

Pengumpulan data meliputi :

1. Teknik kuisioner : dilaksanakan melaluui penyebaran kuisioner kepada seluruh responden yang isian antara lain pertanyaan yang berhubungan dengan kebutuhan penelitian.

2. Metode wawancara : melaksanakan tanya jawab pada sejumlah petani dan PPL dalam rangka menggali informasi terkait penelitian ini.

3. Metode observasi : melaksanakan penelitian atau melakukan pengamatan langsung di lapangan.

4. Metode dokumentasi : menggunakan dokumentasi pada kegiatan penyuluhan sebagai dokumen yang bisa dijadikan bukti. 


\subsection{Analisa Data}

Analisa data ini digunakan dengan cara cross table. Analisis deskripsi dilaksanakan dengan cara mendeskripsikan respon oleh kelompok tani terhadap peran PPL di lapangan.

Dalam menghitung analisa item dan korelasi diantara faktor dipergunakan rumus koefisien korelasi Product Moment Pearson dengan perhitungan program SPPSS 13.00 for windows.

Rumus :

$$
\operatorname{rxy}=\frac{\frac{\sum x y-\left\{\sum x\right\}\left\{\sum y\right\}}{N}}{\sqrt{\left[\frac{\sum x^{2}-\left(\sum x\right)^{2}}{N}\right\}\left\{\frac{\sum y^{2}-\left(\sum y\right)^{2}}{N}\right\}}}
$$

Keterangan:

$\mathrm{rxy}=$ koefisiean korelasi variable $\mathrm{x}$ dengan variable $\mathrm{y}$.

$\mathrm{xy} \quad=$ jumlah hasil perkalian antara variable $\mathrm{x}$ dengan variable $\mathrm{y}$.

$\mathrm{x} \quad=$ jumlah nilai setiap item.

$\mathrm{y} \quad=$ jumlah nilai konstan

$\mathrm{N} \quad=$ Jumlah obyek penelitian

Untuk menentukan tingakat signifikansi, maka digunakan rumus :

$$
\mathrm{T}=\mathrm{rp} \frac{\sqrt{N-2}}{1-r p 2}
$$

Keterangan :

$\mathrm{T} \quad$ : tingkat signifikansi

rp : Koefisien korelasi rank Pearson

$\mathrm{N}$ : Jumlah sampel pengamatan

Perumusan dari hipotesis yang diuji adalah sebagai berikut :

Ho : rp $=0$, berarti:

a. Tidak ada korelasi diantara faktor intern maupun ekstern dengan respon para petani terhadap peran PPL.

b. Tidak ditemukan korelasi antara respon petani dalam hubungannya peran PPL

Pengujian berdasar nilai probabilitas yaitu $<0,05$ maka Ho ditolak, dan jika probabilitas $>0,05$ maka Ho diterima. Adapun sifat korelasi yang menentukan arah 
dari korelasi dapat dikategorikan antara lain :

1. 0,00 s.d 0,20 mengandung arti korelasi mempunyai kesetaraan amat lemah.

2. 0,21 s.d 0,40 mengandung arti korelasi mempunyai keeratan lemah.

3. 0,41 s.d 0,70 mengandung arti korelasi mempunyai keratan kuat.

4. 0,71 s.d 0,90 mengandung arti korelasi memiliki keeratan amat kuat.

5. 0,91 s.d 0,99 mengandung arti korelasi memiliki keeratan amat sangat kuat.

6. I ,00 mengandung arti korelasi sempurna.

\section{HASIL DAN PEMBAHASAN}

\section{Faktor Intern Kelompok Tani}

Faktor intern pada diri petani meliputi antara lain :

1. Stereotip

Suatu keyakinan tentang karakteristik orang atau golongan yang berpenaruh pada penyamarataan kepada para anggota kelompok tersebut. Ini terkait cara respon petani kepada peran PPL yang berfungsi mendampingi kelompok tani. Masing-masing anggota tani mempunyai respon yang berbeda. Beranggapan bahwa peran PPL cukup memberikan nilai keuntungan dan mampu memberikan peran aktif dalam bimbingan kelompok tani dalam berusahatani yang dilaksanakan, namun ada pula sebagian kelompok tani yang beranggapan bahwa kehadiran PPL tidak terlalu penting.

2. Kearifan menyunting stimulus.

Sebuah proses dalam pengambilan keputusan dalam rangka mengadopsi inovasi baru dibidang apapun umumnya dilaksanakan secara musyawarah oleh para PPL, ketua kelompok tani dan seluruh anggotanya. Ada kalanya para PPL tidak ikut terlibat di dalam pengambilan keputusan. Dalam hal ini ketua kelompok mempunyai peran yang amat dominan dalam proses pengambilan keputusan.

3. Konsep diri.

Di lapang dapat diperoleh gambaran para kelompok tani yang memiliki kelsa lebih tinggi umum mempunyai konsep tentang diri yang lebih positif dibanding dengan kelompok yang ada dibawahnya. Konsep tentang diri bersifat positif dapat dilihat pada pada kelompok tani madya antara lain mempunyai ciri-ciri memiliki etos kerja 
dan keyakinan yang cukup kuat dalam mengatasi berbagai permasalahan.

4. Harapan dan Kebutuhan.

Pokok bahasan yang diberikan PPL umumnya adalah bersifat teknik teknih tentang budidaya pertanian. Penentuan berbagai jenis komoditi yang sesuai dengan kondisi lapang, penentuan berbagai jenis saprodi yang sesuai dengan metode Pengendalian Hama Terpadu (PHT). Persoalan pasca panen dan pemasarannya belum diberikan oleh PPL. Padahal persoalan pemasaran membutuhkan penanganan yang komprehensif maupun serius sehingga harapannya para PPL dapat membantu menangani dan memecahkan berbagai masalah terkait pemasaran pertanian.

5. Emosi diri.

Umumnya pelaksanaan penyuluhan yang dilaksanakan pada saat yang tidak tepat akan menciptakan perasaan tidam menyenangkan bagi petani. Dalam hal ini PPL sering mencari informasi daripada menyampaikan informasi, ini tentu menciptakan situasu yang kurang kondusif dari petani..

6. Pengalaman masa lalu.

Selama ini peran PPL pada umumnya lebih bersifat top down policy yaitu merupakan upaya dari pemerintah dalam mensukseskan program pemerintah, seperti Insus, Bimas dan lain-lain. Kadang-kadang PPL menawarkan jasa menjual sarana produksi sehingga terkesan PPL berperan sebagai agen penjual sarana produksi.

\section{Faktor-faktor Ekstern}

Faktor-faktor ekstern berpengaruh pada respon kelompok tani meliputi :

1. Intensitas pertemuan

Intensitas pertemuan ini berkaitan dengan sebuah perhatian PPL kepada kelompok tani yang menjadi binaannya. Di Kalidawir, para PPL umumnya melakukan kunjungan secara rutin dengan jadwal yang telah tertera. Dan ini disesuaikan dengan kebutuhan masing-masing kelompok tani.

2. Frekuensi pertemuan

Frekuensi pertemuan terkait dengan ragam kegiatan dan jumlah kunjungan para PPL dalam hubunganya dengan upaya pembinaan kelompok tani lewat proses penyuluhan. Frekuensi pertemuan merupapak kunjungan yang dilakukan oleh 
PPL antara lain waktu persiapan tanam, waktu pertengahan dan menjelang panen.

3. Ukuran

Inovasi yang dilaksanakan para PPL sesuai dengan ukuran para petani. Sebagai contoh PHT merupakan upaya pengendalian hama terpadu berdasarkan pemakaian predator alami dan ini mampu mengurangi pemakaian pestisidah serta menumbuhkembangkan pemakaian pestisida organik.

4. Pengulangan

Pengulangan berhubungan dengan jumlah penyuluhan atau sosialisasi yang dilaksanakan oleh PPL contohnya pada materi PHT proses penyuluhan atau sosialisasinya dilaksanakan tidak hanya sekali.

\section{Gambaran Umum}

Peran PPL di Kalidawir berdasar prosentase dibagi menjadi tiga, yaitu prosentase lemah $10 \%-30 \%$, prosentase sedang $40 \%-60 \%$, prosentase tinggi $70 \%$ $90 \%$.

Peran Penyuluh Pertanian Lapangan ( PPL) meliputi :

1. Sebagai Pembimbing

PPL sebagai pembimbing kelompok tani dinyatakan punya kategori tinggi bila skornya $71,3 \%$ merupakan skor yang diperoleh dari skor maksimal yang dikehendaki. Sebagai pembimbing, PPL semestinya tahu kondisi yang meliputi ekonomi dan sosial kelompok binaannya. Ini amat penting mengingat menjadi faktor yang menentukan langkah yang akan dilaksankaan PPL dalam memberikan solusi kepada kelompok tani. PPL bisa menjadi seorang penasehat maupun konsultan atau sebagai pengarah kelompok tani untuk mengambil sebuah keputusan saat menghadapi berbagai permasalahan usahatani. Namun demikian kenyataanya pada saat ini di daerah penelitian dimaksud banyak dijumpai keputusan kelompok tani dilaksanakan secara mandiri.

2. Sebagai Organisator

PPL berperan sebagai organisator dengan jumlah skor $60,7 \%$ dari jumlah skor yang dikehendaki. Sebagai organisator, PPL berperan untuk untuk 
menumbuhkan kelompok tani diantaranya banyak berdiri kelompok tani yang baru.

3. Sebagai Dinamisator.

PPL sebagai dinamisator punya kategori tinggi dengan jumlah skor $81,3 \%$ dari skor diharapkan. Ini dapat diketahui dari jumlah frekuensi latihan untuk peningkatan ketrampilan dan pengetahuan serta frekuensi kunjungan kepada kelompok binaannya.

4. Sebagai Teknisi

PPL sebagai teknisi mempunyai kategori sedang dengan jumlah skor $62,3 \%$ dari skor yang diharapakan. Pada realitasnya PPL sering melaksanakan ceramah dalam penyuluhananya, sedangkan masalah terkait praktek secara teknis kemampuan PPL masih kurang.

\section{KESIMPULAN DAN SARAN}

\section{Kesimpulan}

Kesimpulan penelitian ini meliputi :

1. Faktor intern ini terdiri atas stereotip, dalam upaya menyunting terkait stimulus, konsep diri, harapan-harapan dan kebutuhan, emosi diri serta pengalaman di masa lampau tidak berkaitan dengan respon petani. Ini didasarkan dari hasil analisa rumus Product Moment Pearson diperoleh hasil 0,320.

Ini disebabkan karena mayoritas petani di Kalidawir umumnya mempunyai tingkat pendidikan sedang dan mayoritas kelompok tani ini bersifat pemula, sehingga mempunyai konsep diri dan kearifan dalam menyunting stimulus sifatya juga rendah.

2. Tidak korelasi diantara faktor ekstern yang meliputi intensitas, frekuensi maupun ukuran dan pengulangan terhadap respon petani. Ini bisa dilihat dari rumus Product Moment Pearson sebesar 0,801 ini berarti menerima Ho dan berarti tidak ada korelasi antara faktor-faktor ekstern dengan respon oleh petani. Hal ini karena tanggapan petani terhadap peran penyuluh amat rendah serta pengetahuan petani yang cukup minim sehingga dimasa depan harapannya PPL mampu meningkatkan kinerja di bidang penyuluhan. 
3. Terdapat korelasi atau hubungan antara respon oleh petani dengan peran PPL. PPL sebagai dinamisator, organisator dan teknisi maupun pembimbing serta penghubung. Hal ini tentunya dapat dilihat dari hasil analisis didapatkan hasil 0,002. Hubungan keeratan korelasi antara respon petani dengan peran PPL adalah memiliki keeratan yang kuat karena memiliki koefisien korelasi 0,0468. Ini walaupun tanggapan dan pengetahuan petani cukup rendah, namun para PPL mampu memberikan bimbingan kepada para petani sesuai tugas dan fungsi PPL.

\section{Saran}

Saran-saran meliuti :

1. Diupayakan hubungan yang sinergis maupun harmonis antara PPL dan kelompok tani. Hubungan dimaksud diharapkan mampu menambah intensitas perhatian kepada kelompok tani, dengan cara meningkatkan frekuensi kunjungan maupun kegiatan serta peningkatan kemanfaatan materi-materi pertanian lebih intensif dan komprehensif.

2. Dalam rangka melancarkan proses penyuluhan pertanian maka perlu diupayakan peningkatan respon kelompok tani agar mampu menciptakan hubungan yang bersifat timbal balik yang serasi diantara kedua belah pihak, sehingga mampu menciptakan transfer inovasi yang dapat berjalan sesuai dengan harapan. Upaya peningkatan kinerja PPL terkait dengan kebijakan pemerintah, terkait tugas pokok dan fungsi PPL pasca otonomi daerah, ini tentu sangat berpengaruh pada program penyuluhan yang telah berjalan selama ini.

3. Perlunya dilaksanakan peningkatan peran PPL kepada kelompok tani dengan cara kegiatan-kegiatan kelompok tani diaktifkan sehingga mampu membantu para petani dibawah binaan dalam memecahkan berbagai persoalan pertanian.

4. Digali lagi mendalam tentang faktor-faktor yang berpengaruh terhadap respon petani dalam hubungannya peran PPL.

5. Dalam upaya membentuk kelompok tani maka dibutuhkan petani rata-rata yang umurnya produktif, sehingga diharapkan memudahkan dalam transfer tenologi dan inovasi. 


\section{DAFTAR PUSTAKA}

Anonimus, 1992. Buku Latihan Managemen Usahatani. Pendidikan Guru Pertanian PGP Utama IV/1972. Bogor.

Armand Sudiyon, 1992. Ekonomi Produksi Pertanian. Universitas Muhammadiyah. Malang .

Chaplin, CP. 1984. Kamus Besar Psikologi. CV Rajawali Press. Jakarta

Davidov, L, dkk. 1988. Psikologi Suatu Pengantar. Erlangga. Jakarta

Faisal, Sanapiah. 2001. Format-Format Penelitian Sosial. PT. Raja Grafindo Persada. Jakarta

Gema Penyuluhan, No. 9/IV/1980. Proyek Penyuluhan Pertanian - Direktorat Jenderal Pertanian Tanaman Pangan.

Kartasapoetra. 1991. Teknologi Penyuluhan Pertanian. Bumi Aksara. Jakarta

Kusnadi. 1985. Penyuluhan Pertanian Teori Dan Penerapannya. Unibraw. Malang

Mubyarto. 1985. Peluang Kerja dan Berusaha di Pedesaan. BPFE. Yogyakarta. Nazir, Moh. 1985. Metode Penelitian. Penerbit Ghalia Indonesia. Jakarta.

Panirengu, Stefanus. 1989. Diktat Kuliah Perilaku organisasi Fakultas IImu Administrasi. Unibraw. Malang

Parmawati, Rita. 1999. Respon Petani Terhadap Program Pemerintah dalam Pengembangan Usaha Tani Garut. Fakultas Pertanian. Unibraw. Malang

Purwadarminta, WJS. 1984. Kamus Lengkap Bahasa Indonesia. PN Balai Pustaka. Jakarta

Rakhmat, Jalaludin. 1992. Psikologi Komunikasi. PT Remaja Rusdakarya. Bandung

Sanapiah. 2001. Format-Format Penelitian Sosial. PT. Raja Grafindo Persada. Jakarta.

Soedarmanto. 1992. Dasar-Dasar dan Pengelolaan Penyuluhan Pertanian. Fakultas Pertanian. Unibraw. Malang

Soekartawi, A. Soehardjo, John L.Dillion, J. Brian Hardeker, 1986. Ilmu Usahatani dan Penelitian untuk Pengembangan Petani Kecil. Universitas Indonesia. Jakarta.

Suhardiyono. 1990. Penyuluhan Petunjuk Bagi Penyuluhan Pertanian. Penerbit Erlangga. Jakarta

Sutanto, Rachman, 2002. Pertanian Organik : Menuju Pertanian Alternatif dan Berkelanjutan. Jakarta.

Van den Ban A.W. dan Hawkins H.s. 1999. Penyuluhan Pertanian. Kanisius. 
Yogyakarta 